\title{
Osteochondritis Dissecans
}

National Cancer Institute

\section{Source}

National Cancer Institute. Osteochondritis Dissecans. NCI Thesaurus. Code C34878.

Osteochondritis that is characterized by fragmentation of cartilage and bone. 